\title{
SOCIOLOGY OF GENDER MEETS PHARMACY, UNIVERSITY MEETS HIGH SCHOOL: INTERDISCIPLINARITY THROUGH SERVICE LEARNING
}

\author{
Leon Freude, Antonia Collado Sevilla, Núria Vergés Bosch \\ Universitat de Barcelona (SPAIN)
}

\begin{abstract}
We present an interdisciplinary experience of Service Learning, which has been part of the broader project Sharing ideas: the university goes to high school. In this project, university students divulgate, dialogue and contrast knowledge acquired at their university class through the organization of workshops at high schools. In our case, we invited sociology students from the course Sociology of Genders and medicine students doing a Pharmacy course to design an intervention on drug consumption. Our general objective was to innovate university teaching and bring it closer to realworld issues. In concrete we aimed to improve the understanding of course specific content as well as general and specific competences. Concerning competences, we aimed to improve group work, interdisciplinarity, communication and divulgation as well as critical reasoning through contrast of content and dialogue. Concerning content, we wanted our students to learn about gender perspective, gender and drugs, medical and sociological points of view and data analysis. In addition, we wanted to take into account the needs of the community fostering social transformation and agency. Our students defined themselves the objective to empower the secondary education pupils on autonomous and critical decision-making concerning their drug use.
\end{abstract}

Methodologically we based our project on Service Learning, enriching it with the notions of feminist methodologies and public sociology. In order to control both, the community impact, as well as the satisfaction and consolidation of knowledge and competences of our students we opted for a mixed method approach: Our students responded a questionnaire and wrote a final reflection; the secondary students and their teachers responded a mainly quantitative questionnaire.

The results indicate that the participating secondary students and their teachers strongly appreciated the intervention of our students. Our students underline that Service Learning gives them the possibility to concentrate on one topic and contrast it permanently. They consider that the contents are interiorized better, than in a theoretic exam. However, they also indicate that Service Learning implied much more work and admit that the interdisciplinary part has been very difficult.

We can conclude that an interdisciplinary intervention on drugs in the mark of Service Learning is a very promising way to innovate teaching in Gender Sociology and Pharmacy. Teachers should foresee difficulties concerning the inequal effort; difficulties concerning interdisciplinarity need to be worked on, enhancing interdisciplinarity.

Keywords: pharmacy, sociology, gender, drugs, Service Learning, interdisciplinarity.

\section{INTRODUCTION}

Since the last decades of the twentieth century Service Learning is getting more and more extended in higher education in general $[1,2]$. Service Learning has a long tradition in careers related to health management [3], especially nursery ([4], [5], [6], [7]), and gains popularity in sociology ([8]; [9], [10]), too. In the case of social sciences, we detected several references to schools of thought: often Service Learning refers to Charles Wright Mill's concept of sociological imagination ([8]); others invoke the "Chicago school tradition of situating community-based, experiential learning processes at the heart of sociological research" ([9], p. 138).

Service Learning supposes the "integration of course content and community service activities, with an emphasis on student's reflection" ([2], p. 105). Service learning gathers a large amount of topics worked on; it ranges from introduction courses, over race and ethnicity, immigration, inequality, global economy and development, AIDS/HI including even methods ([2]). An important characteristic of Service Learning is that the dialog with real-world issues "corrodes disciplinary boundaries" ([9]) awarding it with great interdisciplinary potential. Some teachers went beyond this inherent interdisciplinarity and designed explicitly mixed Service Learning projects composed by students from 
different disciplines; for example sociologists with social workers ([11]). We want to continue this path and propose to encourage sociology students and medicine students to design a workshop on drugs at a high school together. This is even more suggestive as the medicine students are doing a pharmacy course, while the sociology students are doing Sociology of Genders.

\subsection{Benefits and challenges}

Literature praises Service Learning because of its effects on university students, improving both transversal competences as well as specific substantial knowledge. In this sense, we assume teamwork and communication as key competences, considering that Service Learning is assumed to increase empathy with others ([2]), and helps to understand oneself ([1]). We also know that Service Learning facilitates a better understanding of complex sociological problems such as the structureagency debate ([8], [12], [13]). In addition, the constant dialogue with the other, mentoring and colearning allow the assessment "various forms of expertise, from grounded and experiential, to practical and applied, to abstract and theoretical" ([12], p.69).

Studies also observed a better academic performance ([8]) highlighting "student enthusiasm and participation" ([2], p.105), probably due to the transformation of "students from passive to active learners through community service" ([2], p.105). Finally, research points out that Service Learning projects enable students to explore "careers inside non-profit organizations, social service agencies, and the public sector more general" ([2], p. 105), facilitating their orientation on the job market.

Community just recently became an agent worth an analysis: there has been little research in this area ([10]). The same authors detect that participants' capacities, dedication, high motivation, new perspectives and energy in service are appreciated ([10]). Likewise, literature remarks that if they work with younger people it is easier to connect with the participants who even establish themselves as referents ([10]).

Weak spots of Service Learning turn around "its emphasis on charity and volunteering, rather than citizenship and advocacy, and for the subsequent lack of attention to promoting social change" ([13] p. 126). Taking into account the community, literature questioned Service Learning's ability to create a relationship of mutuality ([1]). Because of "student's unreliability and lack of motivation and commitment" ([10], p. 127), the lack of pedagogical tools ([2]) and initiative ([10]) the ideal "win-win-win situation for the university, students and community" ([10], p. 120) often fails. Therefore bad organized Service Learning projects suppose a drain of "organizational resources" ([10], p. 127).

\subsection{Service Learning, Feminist Methodologies and Public Sociology}

At this point, we propose fructiferous intersections of Service Learning, feminist methodologies and public sociology. Service learning is not necessarily critical and that is one of its main critiques. Public sociology ([14]) claims to be a critical approach, but in contrast to critical sociology it never loses the ground being therefore clearly linked to real world problems ([14]). Whereas public sociology critics generally social inequalities ([14]), feminist methodologies concentrate on specifically on gender inequalities ([15], [16], [17]). This includes androcentrism and, thanks to intersectional approaches other inequalities such as class, race, sexuality or age [17]). All three approaches require dialogue with society: the community turn in the Service Learning, frames the service as something to be requested by the community and the learning process is a dialogic one ([2]; [12]). Public sociology refuses to be an elitist sociology of academic ivory towers, fomenting research, which takes into account people's perspectives. Finally, feminist methodologies are also looking for the dialogue with the other: the experience of androcentricity makes it necessary to hear other silenced voices in order to construct knowledge that is more objective. Concerning social change, both public sociology and feminist methodologies underline its commitment for Social Equality ([14], [15], [16], [17]), in the case of Feminist Methodologies especially gender equality and justice ([15], [16], [17]). In the case of Service Learning, literature enumerates cases in which the commitment for a profound social change is lacking ([13], [18]); anyway, the recent community turn in Service Learning underlines the necessity to link the service with a broader aspiration for social change ([13], [18]). Considering interdisciplinarity, we have to acknowledge that Service Learning is practiced in almost any academic discipline ([19]), but it is not necessarily interdisciplinary. Public Sociology neither invokes interdisciplinary work ([14]). Instead, Feminist Methodologies as well as women's and gender studies reclaim to go beyond the limits of academic disciplines, in order to get a better understanding of the world ([17]). While Service Learning is mainly focused on Learning, linking it to Community, Public 
Sociology concentrates on academic research linking it to Community and Social Movements. Feminist Methodologies direct at research spending special attention to the researcher.

\begin{tabular}{|l|l|l|l|}
\hline \multicolumn{3}{|c|}{ Table 1. Merging Service Learning, with Public Sociology and Feminist Methodologies } \\
\hline & Service Learning & Public Sociology & Feminist Methodologies \\
\hline Critical & $\begin{array}{l}\text { Not necessarily, though } \\
\text { critiques }\end{array}$ & $\begin{array}{l}\text { Necessarily, but not } \\
\text { academic : inequalities }\end{array}$ & $\begin{array}{l}\text { Necessarily, mainly on gender } \\
\text { (intersectional): gender } \\
\text { inequalities; androcentrism }\end{array}$ \\
\hline Dialogical & $\begin{array}{l}\text { Necessarily, different } \\
\text { degrees }\end{array}$ & Necessarily, critical theory & $\begin{array}{l}\text { Necessarily, especially with } \\
\text { women, gendered people, } \\
\text { silenced people }\end{array}$ \\
\hline Social Change & Not necessarily; learning & Equality, justice & Gender equality, gender justice \\
\hline Interdisciplinary & Implicitly, not explicitly & Not at all & inherently \\
\hline Area & Learning \& Community & $\begin{array}{l}\text { Academy, Sociology and } \\
\text { Community }\end{array}$ & $\begin{array}{l}\text { Academy, academics and } \\
\text { women }\end{array}$ \\
\hline
\end{tabular}

Said this, we consider that the weak spots of Service Learning can be more than compensated by Public Sociology and Feminist Sociologies. Therefor we complemented the broader Service Learning project of University of Barcelona with approaches from Public Sociology and Feminist Methodologies.

\subsection{Sharing Ideas}

The project Sharing Ideas. The University goes to high-school consists of a Service Learning Project of the University of Barcelona ([20], [21], [22]). The project has been launched the academic course $2016 / 17$ and is still running. In its framework, any professor of any faculty can offer workshops to high schools linked to their courses' content. A large list of workshops is generated through the different offers of the University teachers, giving the high-schools the possibilities to ask for workshop that responds to their specific needs. However, it is not the university professors doing the workshop, but their students. University students are given the task to develop a workshop deepening a topic of the courses curriculum. They also participate in specific courses on communication and are required to imply themselves in preparation and evaluation. So, they have to make the contact with the high school before their intervention, plan and execute the intervention under the supervision of the university professor, and evaluate the whole process. Through this experience, they are expected to improve the understanding of course specific content as well as general and specific competences.

\subsection{The workshop we worked on: Which drug have I taken?}

The project we analyse here has been titled Which drug have I taken? And aims to deepen the understanding of substance consumption, in order to enable responsible behaviour. We wanted the university students to work in an interdisciplinary way on drugs consumption, fostering a medical understanding of the Sociology students and a social perspective for the medicine students. This social perspective was enriched with a gender perspective.

The workshop Which drug have I taken? Was carried out in the first course of the project Sharing Ideas (2016-17), involving Sociology and Medicine students. The Sociology students were enrolled in a Sociology of Genders course, while the Medicine students were part of a pharmacy course. Two schools for six sessions demanded our workshop. The workshops had an extension between 45 and 90 minutes depending on the high schools' possibilities. The university students were encouraged to design it as participative as possible.

\begin{tabular}{|l|c|c|c|}
\hline \multicolumn{4}{|c|}{ Table 2. Overview of the implied persons in the different workshops } \\
\hline & $11 / 11 / 2016$ & $24 / 11 / 2016$ & $01 / 12 / 2016$ \\
\hline N. Students & 57 & 60 & 60 \\
N. Speakers & 6 & 8 & 8 \\
N. Teachers & 2 & 2 & 2 \\
\hline
\end{tabular}




\section{METHODOLOGY}

In terms of methodology, we already specified in the introduction our approach combining public sociology ([14]) with feminist methodology ([15], [16], [17]), in order to enrich Service Learning as a learning method. A broader social transformation in order to achieve more equality, especially but not only gender equality, is the starting point of our scientific and pedagogical work.

In terms of methods, we defend methodologic pluralism ([23]), mixing up methods, using both, quantitative and qualitative methods. On the one hand, we ask the highschool students and their teachers to fill out a questionnaire right after the intervention, evaluating the workshop mainly quantitatively. On the other hand, we asked the university students to write down their experience, explaining what they did learn and which were the most challenging situations. Also, we took into account the presentation and the planning of the workshop, as well as the final qualification. Retaking the feminist spirit of triangulation of data and points of view, we reach a more valuable evaluation.

In terms of techniques, we did analyze the means of the quantitative evaluations for each workshop. We did the same, disaggregating by sex in order to check if there were different impacts according to sex/gender. Analyzing the university students' experiences, we looked for ideas, which confirm or deny the theory concerning Service Learning. In order to evaluate the consolidation of contents we also took into account the workshop itself.

Our general objective was to innovate university teaching and bring it closer to real-world issues. In concrete, we aimed to improve the understanding of course specific content as well as general and specific competences. Concerning competences, we aimed to improve group work, interdisciplinarity, communication with peers, divulgation, critical reasoning through contrast of content and dialogue. Concerning content, we wanted our students to learn about gender perspective, gender and drugs, sociological point of view, data analysis. In addition, we wanted to take into account the needs of the community fostering social transformation and agency. Our students defined themselves the objective to empower the secondary education pupils on autonomous and critical decision-making concerning their drug use.

\section{RESULTS}

We will proceed now with the discussion of the data, starting with the quantitative material of high school students and teachers. The second part of the article is dedicated to the university students.

The questionnaire asked the high school students to evaluate eight different items of the workshop separately (Interesting topic, Comprehensive content, New content, Useful workshop, Content transmission, Participative dynamics, Receptivity of the students, The way they explain theirselves), as well as a global evaluation of the whole workshop. The scale for the numerical answers is between zero (not at all/very bad) and ten (completely/very good). In the bottom of the evaluation formulary respondents had the possibility to formulate what did they like best and what they did not like. The last question gathered suggestions for topics of other workshops.

The Table 3 resumes the means of the evaluations separately for the three days of the interventions. They also indicate the percentage of men having participated in the evaluation. The first column shows the mean of the evaluation, while second column shows the mean of the girls.

Concerning the student's interest in topic we can detect that they considered it quite interesting. Students also evaluate the comprehensibility positively. One of the lowest marks receives the novelty of the content; however even this item is more than approved. The usefulness of the workshop receives a considerable evaluation, though it is not one of the best marks. The better results are related with our students' competences, such as content transmission and the way they explain their selves. The best evaluated items are participative dynamics in one case and receptivity of the students in the second case. Controlling a possible gender bias, we detected that there were not any statistically significant differences between boys and girls. 


\begin{tabular}{|c|c|c|c|c|c|c|}
\hline \multicolumn{7}{|c|}{ Table 3. High school student's evaluation of the intervention } \\
\hline \multirow[b]{2}{*}{$\%$ of men } & \multicolumn{2}{|c|}{$11 / 11 / 2016$} & \multicolumn{2}{|c|}{$24 / 11 / 2016$} & \multicolumn{2}{|c|}{$01 / 12 / 2016$} \\
\hline & $38 \%$ & Girls & $71 \%$ & Girls & $55 \%$ & Girls \\
\hline Interesting topic & 7,86 & 7,56 & 8,55 & 8,71 & 8 & 7,72 \\
\hline Comprehensible content & 8,21 & 7,88 & 9,13 & 9,57 & 8,84 & 8,92 \\
\hline New content & 6,46 & 6 & 8,05 & 8,11 & 7,14 & 6,2 \\
\hline Useful workshop & 7,07 & 7,13 & 8,33 & 8,43 & 7,03 & 6,48 \\
\hline Content transmission & 8,39 & 8,31 & 9,35 & 9,57 & 8,9 & 8,88 \\
\hline Participative dynamics & 8,21 & 7,88 & 9,63 & 9,86 & 8,83 & 8,68 \\
\hline Receptivity of the students & 8,96 & 8,69 & 9,8 & 9,89 & 9,5 & 9,48 \\
\hline The way they explain their selves & 8,37 & 7,38 & 9,45 & 9,64 & 8,72 & 8,44 \\
\hline Global evaluation & 7,77 & 6,56 & 8,97 & 9,04 & 8,48 & 8,2 \\
\hline
\end{tabular}

The table three shows the high school teacher's evaluation. The first two columns show each teacher's evaluation, while the third column is the mean of both. As we can see the results are magnifique. Just previous information and management gets in one case a very bad result. Instead, all the interviewed teachers consider that the workshop corresponded to the needs of the students, was useful and adapted perfectly to the annual curriculum. They also considered very well the flexibility in responding their student's doubts and valued unanimously with the best mark the transmission of content and the compensability of the vocabulary. Therefore, it is no surprise that the general evaluation is excellent.

\begin{tabular}{|l|ccc|ccc|cr|r|}
\hline \multicolumn{7}{|c|}{ Table 4. High school teacher's evaluation of the intervention } \\
\hline & \multicolumn{3}{|c}{$11 / 11 / 2016$} & \multicolumn{3}{c|}{$24 / 11 / 2016$} & \multicolumn{3}{c|}{$01 / 12 / 2016$} \\
\hline Previous information and organization & 7 & 0 & 3,5 & 10 & 10 & 10 & 10 & 10 & 10 \\
Corresponds with student's needs & 10 & 10 & 10 & 9 & 9 & 9 & 10 & 10 & 10 \\
Corresponds with the annual curriculum & 10 & 10 & 10 & 9 & 9 & 9 & 10 & 10 & 10 \\
Transmission of contents & 10 & 10 & 10 & 10 & 10 & 10 & 10 & 10 & 10 \\
Comprehensive Vocabulary & 10 & 10 & 10 & 10 & 10 & 10 & 10 & 10 & 10 \\
Motivating Methodology & 10 & 9 & 9,5 & 10 & 9 & 9,5 & 10 & 10 & 10 \\
Participative Dynamics & 10 & 9 & 9,5 & 10 & 10 & 10 & 10 & 10 & 10 \\
Flexible resolution of doubts & 10 & 9 & 9,5 & - & - & - & 10 & 10 & 10 \\
Utility & 10 & 9 & 9,5 & 10 & 9 & 9,5 & 10 & 10 & 10 \\
Global Evaluation & 10 & 9 & 9,5 & 10 & 9 & 9,5 & 10 & 10 & 10 \\
\hline
\end{tabular}

Comparing both, high school students' and teachers' evaluations, we can see that both appreciate the intervention, though the teachers' evaluation is much better than the students' evaluation.

Analyzing now the university student's written evaluation we must admit, that our results are scarce. Just one of the eight students handed in his written evaluation. However, we consider that it contents enough valuable information to include it in the evaluation. The only self-evaluation we analyzed is written by a 26 -year-old male sociology student distinguishing between positive and negative aspects. Positively, he stresses to have worked autonomously on a relatively free chosen topic. This has been especially useful for him, as it made him $100 \%$ convinced of the content to explain. On the other hand, he states that this generated much responsibility and he was not sure if they had passed a red line on drug consumption apologia. Also, he appreciates to have entered in dialog with others, both, other peers and the high school students. He consideres quite difficult, though useful, to do most of the content research with peers and to traduce the research results to an easier language. The student praises the task to design an interactive intervention, having learned to convert some theoretical data input in an inclusive and interactive discussion between the high school and university students. 
Finally, he argues that planning and timing the intervention helped him a lot to polish the presentation well.

The first of the three negative aspects he detects is his difficulty to work with groups in a dynamic way. $\mathrm{He}$ observes that it is very difficult to establish a dialog and fears to take too much protagonism, silencing parts of the group. A second point concerns the communication in the group of the university students. Here he detects an enormous difficulty to dialogue with the others, mainly the medicine students. In this sense he doubts, if medicine students understood and agreed with the approach of the sociology students to invoke for a responsible consume. Instead he detected discourses like drugs are bad and consumption will kill you, in the medicine student's parts of the workshop. Also, he detected a difficulty to understand each other, beyond the content. In this sense, he confirms that they often reached false consensus, because of tiredness - not a real agreement. Finally, he remarks that they lacked time to do a profound intervention.

\section{CONCLUSIONS}

In this project we aimed to integrate Service Learning with feminist methodologies and public sociology, in order to design an interdisciplinary Service Learning project that attends broader social transformation and gender, paying special attention to the community. The project aimed to be beneficial for students in terms of both, the comprehension of content as well as the acquisition of competences.

We outline three strengths of the project: first of all, the intent to foster an interdisciplinarian approach in Service Learning. Secondly, the evaluation dotting the project with community perspective and enabling a supervision from different points of view. And thirdly, the mission to combine Service Learning, with feminist methodology and public sociology. On the other hand, we also detected three challenges for doing better in the future: firstly, university student's evaluations should be compulsory in order to have material to control the subjective vision of what has been learned. Secondly, to have a control group which does not participate in Service Learning. Thirdly, to make a closer follow up of the process by the university professors to be able to facilitate solutions.

Our general objective was to innovate university teaching and bring it closer to real-world issues. Specifically we aimed to improve the understanding of course specific content as well as general and specific competences. Concerning competences, we aimed to improve group work, interdisciplinarity, communication with peers, divulgation, critical reasoning through contrast of content and dialogue. Concerning content, we wanted our students to learn about gender perspective, gender and drugs, sociological point of view, data analysis. In addition, we wanted to take into account the needs of the community fostering social transformation and agency. Our students defined themselves the objective to empower the secondary education students on autonomous and critical decision-making concerning their drug use.

Considering the course specific content, we can deduct from their workshops that our students incorporated a gender perspective in their work on drugs. Also, we have seen that they learned something about reasons and effects of drugtaking, both medical and sociological. They also proofed to have learned where and how to gather data, as well as to analyse and present it in an interesting way.

Considering the competences, we have more empirical material to analyse. On the one hand, we dispose of the high school teachers and high school students' evaluation; on the other hand, we can analyse the only university student's self-evaluation. Team work is somehow fulfilled as they worked together on a workshop and imparted this workshop; however, one of the students' evaluation suggests that this groupwork was not really fulfilling. Similarly, we can observe that interdisciplinarity was clearly given: medicine students and sociology students worked successfully on a topic combining views from their own disciplines; nevertheless, the student's reflection indicates that this interdisciplinary work could have been more fruitful.

Taking into account divulgation, we are in front of three proofs, which underline the success: on the one hand, we have the high school students' opinion, which praise a comprehensive content, a good content transmission and a good way to explain themselves. The high school teachers evaluate these competences even better; actually, they mark them with the best note. In addition, the university student's evaluation indicated the task to translate scientific research to a high school workshop as challenging and helpful. In the case of critical reasoning and dialogue, the responses are not that clear. High school students and teachers are very satisfied with the university students' receptivity. 
Actually, high-school students evaluate this item most positively. Instead, the university student's evaluation is more critical: the university student complains that it was difficult to create a participative ambience.

Finally, we also had the objective to respond to the needs of the community fostering social transformation and agency. Our students formulated the goal to empower the secondary education pupils on autonomous and critical decision-making concerning their drug use. First, we have to consider that the design of the Service Learning project implies that it responds to the needs, as it is the high-school which chooses and orders the specific workshop. Therefore, it is not surprising that the high school teachers considered the workshop responds to both, the needs of the students, as well as the curriculum. However, the high-school students mark the novelty of the workshop's content worst than any other item. Concerning impact, both high school students and teachers evaluate the workshop as useful. One of the weak spots of Service Learning has been that is often means a drain of resources to the community. Therefore, we asked the high school teachers how they evaluate the information and management before the workshop. The responses are very divers and extreme: four teachers mark best note, one of them the worst possible mark and another a 7 .

Finally, we need to comment two more issues. Firstly, we have detected no gender bias in the highschool students' evaluation: there are no statistically significant differences between the girls' and the boys' punctuations. Secondly, we would like to point out the differences in the evaluation between high-school students and high-school teachers, concerning the marks on the necessity of the workshop and its usefulness. While the high-school teachers consider the workshop very necessary and very useful, the high-school students consider the workshop just regularly useful and its content somehow new. These results raise again issues on who is the subject of the community in Service Learning, remitting us to the discussions of feminist research.

Overall, we make a positive balance of the intervention. We reached to innovate university teaching, bring it closer to real-world issues and make it beneficial for an extra-universitarian community. In terms of content, our students applied the gender perspective, work on data analysis and presentation as well as the sociological point of view, besides the central topic drug and gender. Considering competences, the results are very good concerning communication and divulgation of scientific content. Instead, group work and interdisciplinarity have been evaluated less positive by the only student's feedback. Critical reasoning and dialogue have been evaluated very positively by highschool students and their teachers, but less positive by the university students. The community, high school teachers and students differ in the degree of intervention's necessity and usefulness. The highschool teachers consider it well organized.

Therefore, we can confirm that linking Service Learning with public sociology and feminist methodology, as well as interdisciplinarity, is adequate in order to train competences and content. However, further research is still needed if we are to overcome some of its main limitations.

\section{ACKNOWLEDGEMENTS}

The present paper has been developed in the marc of the project Sharing Ideas: The University goes to high school. (2015PID-UB/150) and the context of the INCASI Network, a European project Horizon2020 (Marie Sklodowska-Curie GA No 691004) coordinated by Pedro López Roldán.

\section{REFERENCES}

[1] Huisman, K. "Developing a sociological imagination by doing sociology: A methods-based servicelearning course on women and immigration". In Teaching sociology, 38(2), pp. 106-118, 2010.

[2] Hochschild Jr, T. R., Farley, M., \& Chee, V. "Incorporating sociology into community service classes". In Teaching Sociology, 42(2), pp. 105-118, 2014.

[3] Parsi, K., \& List, J., "Preparing medical students for the world: Service Learning and global health justice". In The Medscape Journal of Medicine, 10(11), pp. 268, 2008.

[4] Beal, J. A., "Academic-service partnerships in nursing: an integrative review". In Nursing Research and Practice, 2012, 2012.

[5] Kemp, C. E., "Community health nursing education: Where we are going and how to get there". In Nursing Education Perspectives, 24(3), pp. 144-150, 2003. 
[6] Redman, R. W., \& Clark, L., "Service-learning as a model for integrating social justice in the nursing curriculum". In Journal of Nursing Education, 41(10), pp. 446-449, 2002.

[7] Cohen, S. S., \& Milone-Nuzzo, P. "Advancing health policy in nursing education through Service Learning". In Advances in Nursing Science, 23(3), pp. 28-40, 2001.

[8] Garoutte, L., "The Sociological Imagination and Community-based Learning: Using an Assetbased Approach". In Teaching Sociology, 46(2), pp. 148-159, 2018.

[9] Rondini, A. C., Observations of critical consciousness development in the context of ServiceLearning. In Teaching Sociology, 43(2), pp. 137-145, 2015.

[10] Blouin, D. D., \& Perry, E. M., "Whom does Service Learning really serve? Community-based organizations' perspectives on Service Learning". In Teaching Sociology, 37(2), pp. 120-135, 2009.

[11] Rooks, D., \& Winkler, C., "Learning interdisciplinarity: Service learning and the promise of interdisciplinary teaching". In Teaching Sociology, 40(1), pp. 2-20, 2012

[12] Marullo, S., Moayedi, R., \& Cooke, D., C. "Wright Mills's friendly critique of Service-Learning and an innovative response: Cross-institutional collaborations for community-based research". In Teaching Sociology, 37(1), pp. 61-75, 2009.

[13] Mobley, C., "Breaking ground: Engaging undergraduates in social change through Service Learning". In Teaching Sociology, 35(2), pp. 125-137, 2007.

[14] Burawoy, M., "For public sociology". In American sociological review, 70(1), pp. 4-28, 2005.

[15] Harding, Sandra. (1987). Is there a Feminist Method? En Sandra Harding, Feminism and Methodology. Bloomington: Indiana University Press.

[16] Bartra, Eli. (1998). Reflexiones metodológicas. En Eli Bartra, Debates en torno a una metodología feminista, 141-158. D.F.: Programa Universitario de Estudios de Género-UNAM.

[17] Biglia, B., \& Vergés Bosch, N., "Cuestionando la perspectiva de género en la investigación". REIRE. In Revista d'Innovació i Recerca en Educació, 2016,. 9, 2, pp. 12-29, 2016.

[18] Fletcher, E. H., \& Piemonte, N. M., Navigating the Paradoxes of Neoliberalism: Quiet Subversion in Mentored Service-Learning for the Pre-Health Humanities. In Journal of Medical Humanities, 38(4), pp. 397-407, 2017.

[19] Zlotkowski, E., "Service-Learning Research in the Disciplines". Michigan Journal of Community Service Learning, 2000.

[20] Amat, A. F., \& Miravet, L. M. "El Aprendizaje Servicio en la Universidad: una estrategia en la formación de ciudadanía crítica". In Revista electrónica interuniversitaria de formación del profesorado, 13(4), pp. 69-77, 2010.

[21] Amat, C., Arias Sampériz, B., Asensio, J. A., Ballesteros Pérez, E., Costa Cuberta, M., i Chéliz, C.\& Fatjó-Vilas Mestre, M. "Compartir ideas, la universidad va al instituto. Análisis de la primera edición de un proyecto de aprendizaje servicio transversal a la Universidad de Barcelona". In Revista del CIDUI, 2016, 3, pp. 1-9, 2016

[22] Morín Fraile, V., Sancho, R., Vázquez Archilla, M., Sarria Guerrero, J. A., Estrada Masllorens, J. M., Galimany Masclans, J., \& Maestre González, E., "Aprendiendo a educar para la salud a través del aprendizaje servicio. Compartir ideas, la universidad va al instituto". Revista del CIDUI, 2016, num. 3, pp. 1-8, 2016

[23] Domínguez Amorós, M., \& Simó i Solsona, M., Tècniques d'investigació social quantitatives. Barcelona: Edicions Universitat de Barcelona, 2003. 